plugs in the treatment of otitis externa in divers, but that the last comment in the article, "diving must be forbidden until the skin has returned to normal," is more appropriate? - I am etc.,

C. R. LUCAS

Southsea, Hants

SIR,-In your leading article which discusses external otitis associated with prolonged contact with water (27 July, p. 213) you suggest that divers might avoid such contact by the use of Vaseline-coated ear plugs. I think the opinion of most divers is that ear plugs should not be used under any circumstances -firstly, because the pressure exerted by the water is quite sufficient to push an ear plug into the deeper part of the meatus, thus necessitating surgical removal; secondly, if the plug is sufficiently impacted in the external meatus the pressure in the middle ear will cause considerable pain and possibly perforate the ear drum. Perhaps Vaseline alone swabbed around the meatus before diving would prevent the maceration of the skin which you describe.-I am, etc.,

London Hospital Medical College

T. SMYTH

You state that the Pickwickian syndrome occurs in some $10 \%$ of obese subjects, but unfortunately this is not substantiated by any reference in the text to published work and may well be an over-estimate. In our experience the Pickwickian syndrome is rare, though mare commonly obesity complicates the alveolar underventilation found in some chronic bronchitics. While the syndrome is fascinating, we feel that it should not predominate in a discussion of the respiratory complications of obesity, for the inequality of ventilation and blood flow to which you refer remains a constant cause of hypoxaemia in the obese, becoming especially important when added to by other factors such as abdominal surgery.

Though Charles Dickens described the fat boy Joe, after whom the syndrome is named, in The Pickwick Papers in 1837, few realize that two cases were described in the eighteenth century by Dr. John Fothergill. One of these was cured by weight loss and in the other "all the viscera were perfectly sound" at necropsy. This was pointed out by Simpson in 1958' but Joe continues to enjoy medical as well as literary immortality. -We are, etc.

Newcastle upon Tyne

G. J. R. MGHARDY

SIR,-While unable to claim an infallible cure for the problem of swimmers' ears I can offer a method of prophylactic treatment as far as I am aware entirely successful in the group of swimmers and divers with which I have been associated. Exposure to water consisted of weekly sea dives (Monterey Bay, California) to average depths of $50 \mathrm{ft}(15.2 \mathrm{~m})$ together with two or three dips a week in private chlorinated poolsperhaps half this rate in winter. Treatment consisted in dropping into the ears three to four drops of $1 \%$ acetic acid in alcohol. This dessicates the sodden epithelium and re-establishes the slightly acid pH, which I am told is desirable.

An itchy ear usually indicates an excessive collection of cerumen or scales, and I have not yet had cause to regret recommending their removal by gentle manipulation of a "Q-tip" or cotton bud. While this is vastly better than a dirty finger nail one must always stress the gentleness.

I am not sure of the reasoning behind your caveat (27 July, p. 213) against dessicants, unless your comments were applied to the established disease. My recommendations, I would emphasize apply only prophylactically.-I am, etc.,

West Dulwich,
London S.E.21

J. A. LACK

\section{Respiratory Complications of Obesity}

SIR,-We were interested to read your leading article on this topic (8 June, p. 519). We think it is worth stressing that in obese persons with normal lungs the increase in resting ventilation is generally appropriate to the increased carbon dioxide production and oxygen uptake, in contrast to the disproportionate increase in alveolar ventilation found in some other conditions (for example, pulmonary thromboembolic disease $^{1}$ ) and also in contrast to the decrease found in the Pickwidkian syndrome. with avoidable factors only and not percentages of the total deaths. The report shows that in $32 \%$ of all deaths an avoidable factor was considered to be present.

As you will appreciate, the situation is less serious than would appear from your article and I would be grateful if this could be made clear.-I am, etc.,

Edinburgh

1 Scottish Home and Health Department, A Report on an Enquiry into Maternal Deaths in
Scotland 1965-1971. Edinburgh, H.M.S.O. 1974.

**We regret our error.-ED., B.M.f.

\section{Death in Foopital}

SiR,-In answer to Dr. J. D. W. Whitney and others (6 July, p. 45) he may be interested in why I do not notify general practitioners of deaths by telephone. On phoning

\section{Northern Counties Chest Hospital,}

practitioners in South London I am usually answered by receptionists, deputizing agencies, or the telephone operator offering me another number which will probably turn out to be a deputizing service.

(1) While cleft lip with or without cleft
After tracking down the owner of ane of the local lock-up surgeries there is a pause before a slightly embarrassed admission that he couldn't quite visualize the deceased but, "thanks all the same, old chap." Disheartened I replace the receiver remembering that in fact the patient had been admitted via the Emergency Bed Service and the deputizing service.

Finally I would counter Dr. Whitney's requests with two from the hospital end. Firstly, the ending of all deputizing services and secondly, even more important to good communications between us, the abolishment of the E.B.S., the bane of all admitting officers.-I am, etc.,

Sudbury, Suffolk

Christopher J. BenNetT

\section{Cleft Lip and Palate}

SIR,-Some of the statements in Mr. I. F. K. Muir's useful article (13 July, p. 107) may be disputed. palate (C.L.P.) or, more commonly, isolated cleft palate (C.P.) occurs as part of many recognizable syndromes, some of which are mendelian, there seems to be no evidence of a recessive contribution to cases of C.L.P. without associated malformations. The genetic contribution in the majority of these appears to be polygenic.1 2

(2) C.P. is commoner in girls than boys but is by no means confined to females, even in the familial cases, as Mr. Muir states. Male index cases with affected sibs have in fact been observed and had a higher proportion of affected sibs $(6 \%)$ than female index cases $(2 \%)^{1}$-evidence of polygenic inheritance in this group.

(3) Statements like "it is very likely that any further female children will have clefts" or "the dangers of further children being affected are very great indeed" may be misleading in genetic counselling, and numerical estimates should be given where possible. Empirical risk figures for various types of family are available. ${ }^{1-3}$ These indicate that in a family with one child and a first-degree relative of one or other parent affected by C.I.P. the risk to a further child is approximately one in 10 and not one in 80 as Mr. Muir states.-I am, etc.,

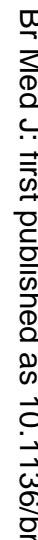

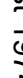

A

M.R.C. Clinical Genetics Unit,

N. R. DEnNIS

London W.C.1

Fraser, F. C., American foumal of Human Genetics, 1970, 22, 336.
Carter, C. O., British Medical Bulletin, 1969, 25, 52. 8,65 .

\section{Removal of Tattoos}

SIR.-Mr. B. D. G. Morgan (6 July, p. 34) describes the removal of tattoos by various plastic methods. I wonder whether other surgeons are aware of the fact that it is possible to do this in a muah simpler fashion by using a power dermatome. With this it is possible to split the dermis and so remove the tattoo leaving unpigmented dermis 